\title{
In Defense of Stamp Collecting: The Importance of Case Studies for Geology Teaching ${ }^{\dagger}$
}

\author{
Carlos Alves \\ LandS/Lab2PT (Landscape, Heritage and Territory Laboratory), UID/AUR/04509/2013, POCI-01-0145-FEDER- \\ 007528, and Earth Sciences Department, School of Sciences, University of Minho, 4710-057 Braga, Portugal; \\ casaix@dct.uminho.pt; Tel.: +351-253-604-300 \\ † Presented at the 1st International Electronic Conference on Geosciences (IECG 2018), 15-30 June 2018; \\ Available online: https://sciforum.net/conference/IECG_2018.
}

Published: 13 June 2018

\begin{abstract}
It is attempted to present here a hopefully illustrative discussion of the use of single images (treated here as stamps representing case studies) in the teaching of diverse geological concepts, based on outcrops and products of anthropogenic activity.
\end{abstract}

Keywords: observations; epistemology; field work; built environment

\section{Introduction}

The expression "stamp collecting" is commonly used in a derogatory way to describe study areas that frequently rely on case studies and observations, sometimes resulting from chance, which can be perceived as akin to a mere accumulation of facts without value for theories or as being only usable in an inductive perspective. However, even the main opponent of inductivism of the last century, Karl Popper, admitted that "some [scientists] may get their ideas by observing, or by repeating observations" [1] (albeit this was put at the same level of getting ideas from smoking or drinking coffee or whisky). However, even what was perhaps the example most frequently referred by this great philosopher of science (Einstein's theory of relativity) benefitted from something that can be, almost literally, described as a "stamp" result (Eddington's image of an eclipse). In the geosciences there is a long history of the relevance of case observations that can serve to refute models or to catalyze ideas, namely for features that cannot be replicated under controlled experimental conditions (one can see the similarities with the eclipse observation for the theory of relativity). Illustrative classic cases can be found in Lyell [2]. For example, in Chapter IV, Lyell presents the logical principles of relative dating using stamps (the question of the rejection of the Neptunists' views is more complex, in my view). A very eloquent stamp was proposed for the rejection of Werner's proposal regarding the relative age of the porphyry: "Thus, for example, within a day's journey of his school, the porphyry, called by him primitive, has been found not only to send forth veins or dikes through strata of the coal formation, but to overlie them in mass". In a converging vein, one can recall the case of the age of Earth (see [3,4]), which geologists at the end of the 19th century suggested was very old after looking at so many stamps (including stamps that showed changes through time, which will be referred to here as $4 \mathrm{D}$ stamps), an idea strongly opposed and "discredited" by Kelvin's physical-mathematical model, which proposed an "age estimation" (a number!), pointing to between 20 and 400 million years (perhaps Kelvin did not look carefully at the stamps?).

The present work aims to present an overview of examples illustrating how case observations can contribute to the teaching of geology, based in the author's own experience concerning both rock outcrops and stones present in the built environment. The examples presented will concern 
diverse study areas, namely mineralogy, geomorphology, geochemistry, petrology, ore deposits, engineering geology and mineral exploration. These case observations will also be used to highlight the importance of the discussion of hypotheses and critical thinking.

\section{Case (Stamp) Organization}

The first issue that will be discussed in this communication concerns the organization of the illustrative cases (stamps) considered. One option was to organize them by concept or subject. However, each of the cases presented here can serve to discuss diverse subjects and issues. My research experience has perhaps biased me to organize the stamps according to a perspective related to the anthropogenic influence: outcrops, anthropogenic rock-cuts, built structures and anthropogenic analogues (these categories will be explained in the following sections).

\section{Outcrops}

The term outcrop will be used in what I believe to be its classic meaning, namely portions of geological objects in expositions that are not the result of human action. Outcrops are the classic founding objects of geology and the large majority of geological studies are based on them (even if this seems to be changing). The perspective here is to look for and collect the largest amount of stamps, and there are recommendations for field recognition that amount to a kind of stampcollecting rules (see, e.g., the classic work of Compton [5]). However, paraphrasing the words of Laznicka [6] in relation to mineral exploration, "everything goes" as long as it leads to new discoveries (which will be suited to the stamp collecting perspective). An example is presented in Figure (stamp) 1, showing the typical boulder weathering of granitic massifs. This view can also be used to discuss hazards related to the movement of rock boulders, and similar stamps were used by Sanjurjo-Sánchez and Alves [7] to discuss the potential advantage of such processes to obtain stones suitable for the building of structures with minimal processing.

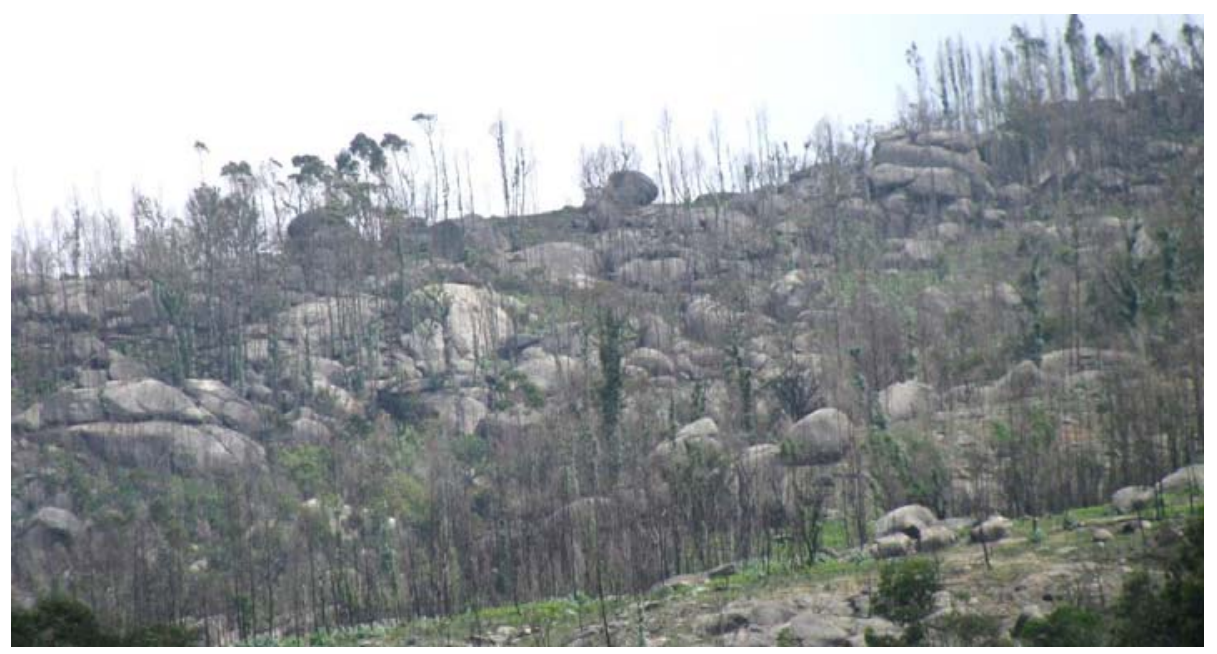

Figure 1. Observation of granite outcrops in mountains around the town of Braga (NW Portugal).

However, outcrop observation has undergone a major change in recent years due to freely and easily accessible (with equipments that cost under 100 USD) aerial views, which are available through diverse online sites. For example, the use of Google Maps can show a wide region where it is possible to identify the presence of extensive rock masses and structures within them (https://goo.gl/13SQ3X). By increasing the observation scale (https://goo.gl/7pAXD2) it is possible to get an assessment of rock block size.

\section{Anthropogenic Rock-Cuts}

This category corresponds to surfaces cut in rock masses by human action (roads, quarries and mines). They offer fresh stamps in directions and depths that are frequently unavailable in 
outcrops. Tools like Google Maps can be also useful here, namely when combined with "street view" (generally not available for outcrops). For example, one could in the past (this specific rock cut is no longer available online) combine the plan available at https:/goo.gl/z6VQcb with the "street view" available at https://goo.gl/maps/T1jHE1fk7212 and at https://goo.gl/maps/EzLnnqnDGTF2 to show the effect of the direction of the available rock surface on joint density (lower in the first case where the road slope azimuth is nearer the main joint family direction), as well as other issues, such as the conditions for planar failure (which changes within the same rock mass according to slope azimuth). There is another use of these online tools that was implicitly introduced by the comment above regarding the present unavailability of the rock-cut online, namely 4D stamps, showing evolution through time (this will also feature in the two following categories). Another example is discussed in Sanjurjo-Sánchez and Alves [7], which compares images of different times of the road slope presented in Figure $2 b$. The image in Figure $2 b$ can be also compared with the Google "street view" image from November, 2014 (https://goo.gl/maps/bBNNCjDYt992), in which the intense development of biological colonization is visible (this image can also be used to exemplify examples of natural mitigation). Besides more traditional geological observations, anthropogenic rock cuts frequently also allow the observation of the implementation of procedures to deal with geological hazards, namely in relation to mass movements. The examples presented in Figure 2 can be used to present concepts related to geological structures (bedding, rock joint families), the weathering degree of rock masses and their products (which can be related to the development of mineral deposits), the presence of rock boulders within saprolite zones (relevant for discussions of geotechnical surveys), the characteristics of rock masses with relevance for geotechnical classifications (such as those presented in Hoek [8]), including joint length and joint walls coating (which can be related to mineralogical concepts), conditions for rock failure (planar and wedge failure are visible) and interventions to minimize these hazards (metallic net).

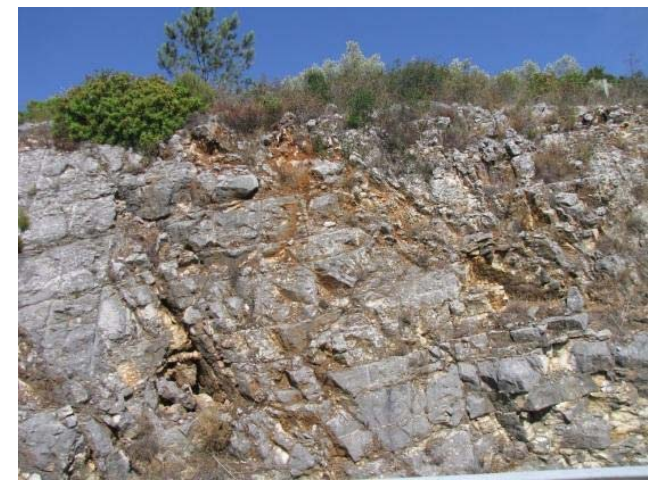

(a)

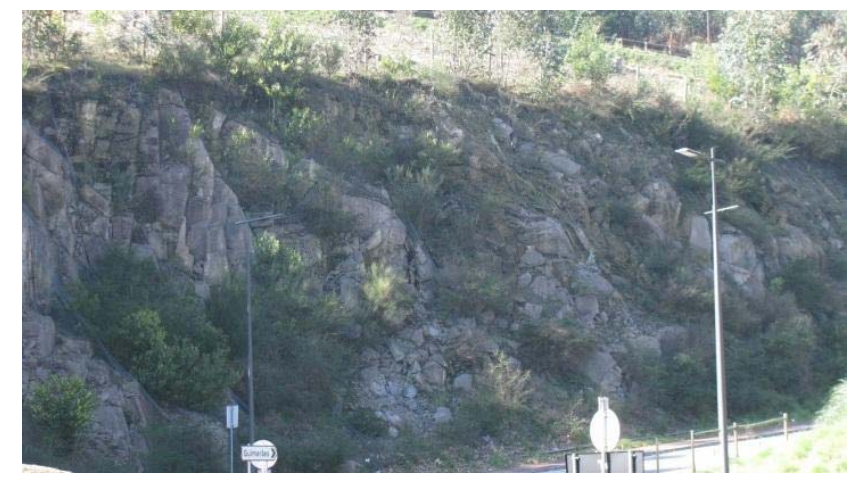

(b)

Figure 2. Stamps showing anthropogenic rock-cuts: (a) road slope on a limestone mass showing the bedding, joints and the effects of weathering (terra rosa); (b) road slope on a granite mass showing jointing that can promote rock movements, supporting net (to minimize this hazard) and natural recovery of vegetation.

\section{Built Structures}

While the previous categories concerned exclusively the local (in fact in loco) geological products, this category, and the next one, can offer exotic stamps from faraway lands, showing processes that are absent in the human-free geological local context (what Hazen et al. [9] refer to as anthropogenic xenoliths).

Figure 3a shows a stamp from the center of Braga, Portugal, where granite stones similar to the local rock are juxtaposed with stones from very exotic rocks that, furthermore, serve to illustrate structural features. Figure $3 b$ shows another exotic stone (a marble stone in a granite region), where one can additionally see planar structures, illustrating the apparent variation of the dip, according to plane of view. In Figure $3 c$ it is possible to observe a pegmatite veinlet discordant on the granite 
with tourmaline crystals (which can also be useful to discuss the concentration of incompatible elements on pegmatites). Some stamps of built structures can also suggest implicitly interesting features of rock masses: Figure 3d shows a façade with slightly yellowed (weathered) granite but perhaps the most striking feature is the very big monolithic columns, which required blocks of great size. The comparison of granite stones in different structures or within the same structure can help to illustrate textural and mineralogical variations as well as different weathering degrees of the same kind of rock; some historical structures are particularly interesting as the builders used stones from different places.

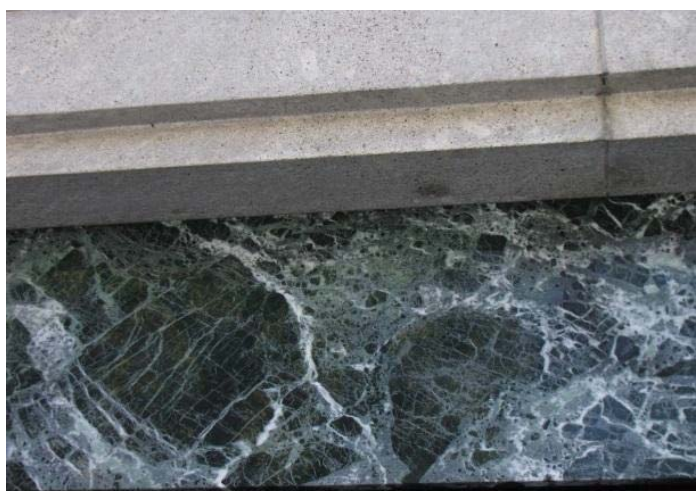

(a)

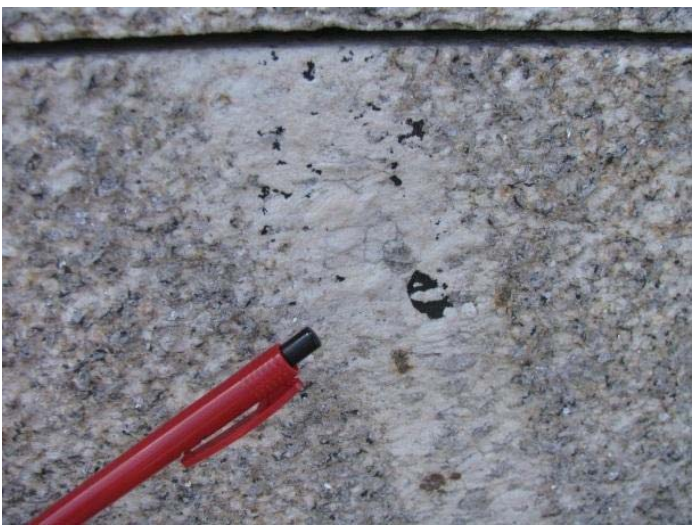

(c)

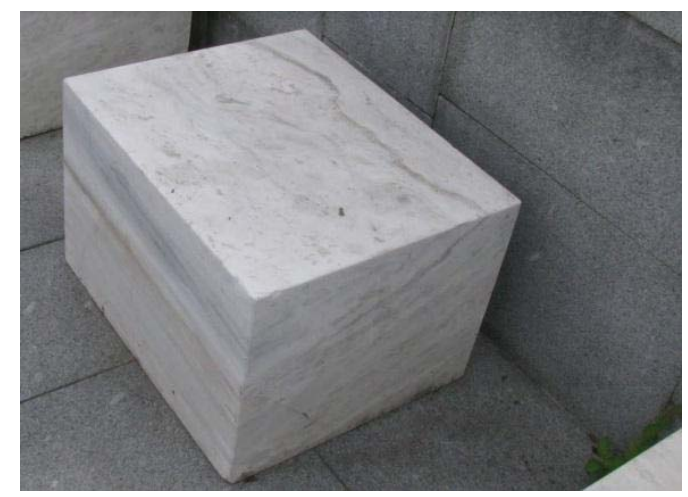

(b)

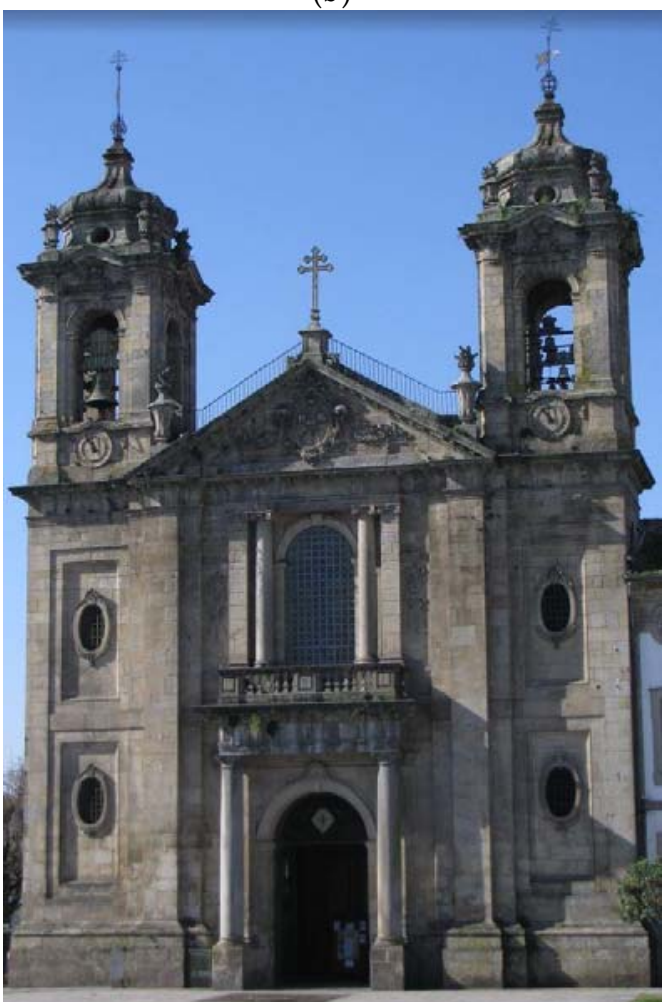

(d)

Figure 3. Stamps showing built structures: (a) Juxtaposition of granite stones (similar to the local stone) and exotic green breccia; (b) marble block with planar structures that illustrate an apparent variation of dip with view plane; (c) pegmatite veinlet on a granite stone; (d) image of the main façade of the Populo's church in Braga (Portugal).

\section{Anthropogenic Analogues}

This section comprises cases that are related to anthropogenic action and that might be not considered "geological" from a more traditional point of view (see discussion in [10]), but which can, nonetheless, be used to illustrate geological processes and products. All the cases considered are unintended consequences of anthropogenic action; the lack of intention being a critical issue in 
the delimitation, as discussed in Alves [10], based on considerations from Lyell [1], Emerson [11], Popper [12] and Dawkins [13]. Figure 4a illustrates stains related to sulfide oxidation (which can be used to discuss such issues as mineral exploration and the impact of mine wastes). Furthermore, this image also serves to discuss some limitations of this kind of stamp (and stamps in general). In some cases, the stain is contained within a single stone (and it can be discussed whether the stain was presented before the stone's emplacement or developed afterwards), while in others the stain crosses the limits between stones (allowing to introduce a discussion of the principle of intersection). Figure $4 \mathrm{~b}$ shows the effects of erosion along structural features (stratification), as well as illustrating the relationship between substrate characteristics and the start of biological colonization. As a closing example, I have attempted in Figure 4c,d something similar to what Taleb did with a lens cap in [14], with one stamp showing what looks like a place where travertine or tufa is forming (Figure $4 \mathrm{c}$ ), while in Figure $4 \mathrm{~d}$ one can see that this occurs in stair steps of the built environment. This last example illustrates a particularly important feature of anthropogenic analogues, as they can illustrate the process of formation of exotic geological substances (see [15]). The example in Figure 4c-d can also be used for 4D stamps in relation to processes (as is discussed in relation to carbonate crusts in Alves and Sanjurjo-Sánchez [16]). An example of the use of online tools for 4D stamps from the built environment has already been provided in [10], in relation to biological colonization. Finally, the example of Figure 4c-d also serves to highlight the care that must be used with anthropogenic analogues, since these crusts presents clear genetic differences in relation to classic carbonate deposits [17]. These differences can also be helpful in teaching perspectives, for example, in this specific case, to introduce the issue of carbon sequestration.

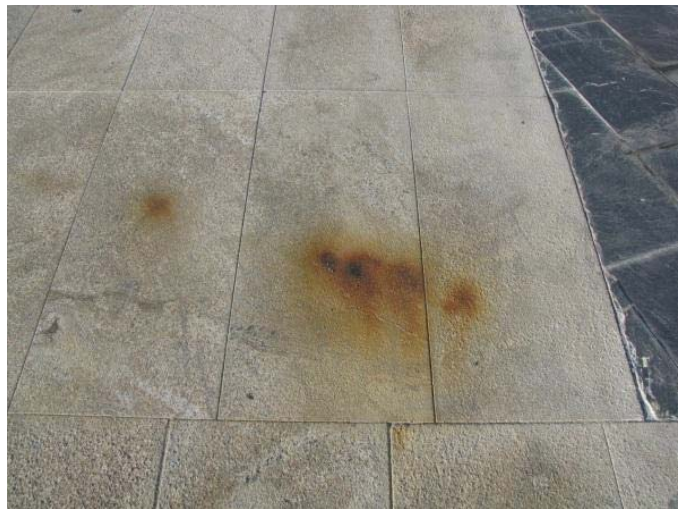

(a)

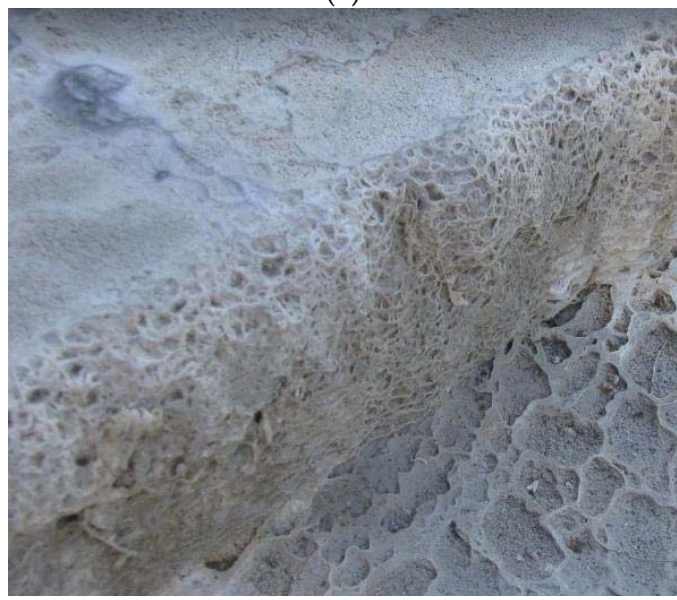

(c)

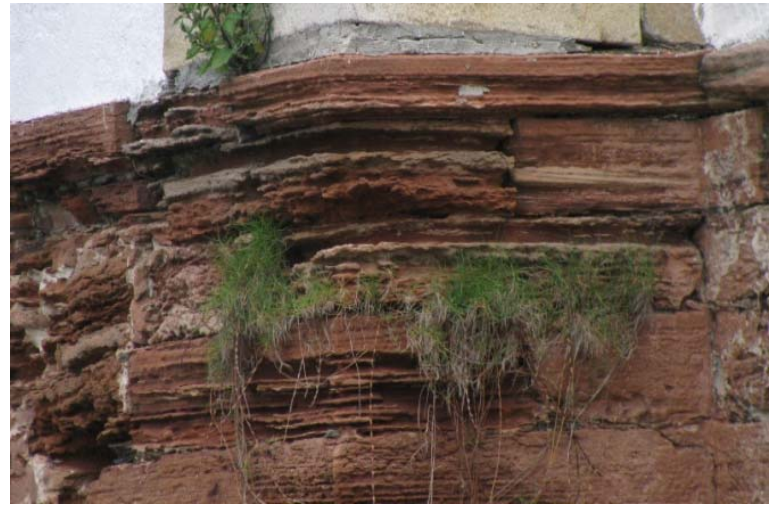

(b)

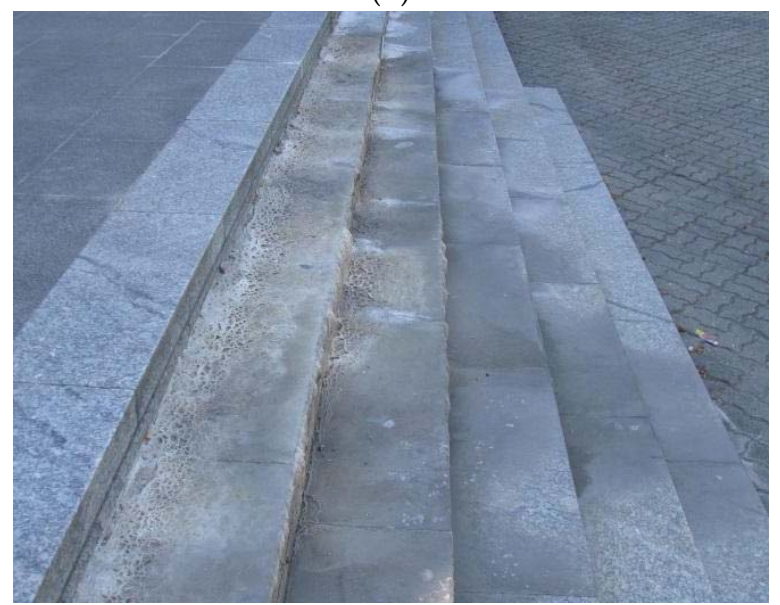

(d)

Figure 4. Stamps showing anthropogenic analogues: (a) stains from oxidation of sulfides on granite stones; (b) erosion along stratification planes and biological colonization; (c) image of calcium carbonate deposition (a kind of "travertine" or "tufa" in the built environment); (d) zoomed-out image showing the context of the previous precipitate, which was found on stairs. 


\section{Conclusions}

It is proposed that the cases (stamps) presented here, from traditional outcrops to unintended anthropogenic analogues that might be frowned upon from a more traditional geological perspective, serve to show diverse potential situations related to observations that are useful when teaching the geological concepts associated with processes and products (as well as highlighting limitations related to scale effects and the specific features of the anthropogenic analogues).

Acknowledgments: The Lab2PT - Landscapes, Heritage and Territory Laboratory-AUR/04509 is supported by the Portuguese "Fundação para a Ciência e a Tecnologia" (Portuguese funds and where applicable, FEDER co-financing, under the new partnership agreement PT2020 and COMPETE2020-POCI 010145 FEDER 007528).

Conflicts of Interest: The author declares no conflict of interest.

\section{References}

1. Popper, K.R. Realism and the Aim of Science: Postscript to the Logic of Scientific Discovery; Routledge: London, UK; New York, NY, USA, 1983; ISBN 978-0-415-08400-0.

2. Lyell, C. Principles of Geology: Or, the Modern Changes of the Earth and Its Inhabitants Considered as Illustrative of Geology; D. Appleton \& Co.: New York, NY, USA, 1853.

3. Pilkey, O.H.; Pilkey-Jarvis, L. Useless Arithmetic: Why Environmental Scientists Can't Predict the Future; Columbia University Press: New York, NY, USA, 2007; ISBN 978-0231132138.

4. Livio, M. Brilliant Blunders: From Darwin to Einstein-Colossal Mistakes by Great Scientists That Changed Our Understanding of Life and the Universe; Simon \& Schuster: New York, NY, USA, 2013.

5. Compton, Robert R. Geology in the Field; John Wiley: Hoboken, NJ, USA, 1986; ISBN 0471829021.

6. Laznicka, P. Giant Metallic Deposits Future Sources of Industrial Metals; Springer: Berlin, Germany; London, UK, 2010; ISBN 978-3-642-12405-1.

7. Sanjurjo-Sanchéz, J.; Alves, C.A.S. Sustainability of Stone Materials in the Built Environment of Rural Regions: A Review. Cad. Lab. Xeol. Laxe 2017, 39, 141-164.

8. Hoek, E. Practical Rock Engineering. 2007. Available online: https://www.rocscience.com/ documents/hoek/corner/Practical-Rock-Engineering-Full-Text.pdf (accessed on 28 May 2018).

9. Hazen, R.M.; Grew, E.S.; Origlieri, M.J.; Downs, R.T. On the mineralogy of the "Anthropocene Epoch". Am. Mineral. 2017, 102, 595-611, doi:10.2138/am-2017-5875.

10. Alves, C. Geoscience of the Built Environment: A Contribution for the Perspectives on the Anthropocene. In Horizons in Earth Science Research; Veress, B., Szigethy, J., Eds.; Nova Science Publishers Inc.: Hauppauge, NY, USA, 2017; Volume 17, pp. 37-72, ISBN 978-1-53612-831-4.

11. Emerson, R.W. Nature; James Munroe and Company: Boston, MA, USA; Cambridge, MA, USA; 1849.

12. Popper, K.R. O Conhecimento e o Problema Corpo Mente; Portuguese Translation (2002) of "Knowledge and the Body Mind Problem: In Defence of Interaction"; Trandslated by Gomes, J.A.F.; Edições 70: Lisbon, Portugal, 1994.

13. Dawkins, R. Climbing Mount Improbable; Penguin Books: London, UK, 1996; ISBN 978-0-14-102617-6.

14. Taleb, N.N. The Black Swan: The Impact of the Highly Improbable, 2nd ed.; Random House Trade Paperbacks: New York, NY, USA, 2010; ISBN 978-0-8129-7381-5.

15. Alves, C. Geochemistry of the built environment: Alteration products of stony materials. In Advances in Geochemistry Research; Sanjurjo-Sánchez, J., Ed.; Nova Science Publishers: New York, NY, USA, 2013; pp. 27-58, ISBN 978-1-62618-245-5.

16. Alves, C.; Sanjurjo-Sánchez, J. Conservation of stony materials in the built environment. Environ. Chem. Lett. 2015, 13, 413-430, doi:10.1007/s10311-015-0526-2.

17. Liu, Z.; He, D. Special speleothems in cement-grouting tunnels and their implications of the atmospheric $\mathrm{CO}_{2}$ sink. Environ. Geol. 1998, 35, 258-262, doi:10.1007/s002540050312.

(C) 2018 by the authors. Licensee MDPI, Basel, Switzerland. This article is an open access article distributed under the terms and conditions of the Creative Commons Attribution (CC BY) license (http://creativecommons.org/licenses/by/4.0/). 